GrZEgORZ ZiNKIEWICZ

University of Lodz

\title{
A NEW ENQUIRY CONCERNING THE OLD WORLD
}

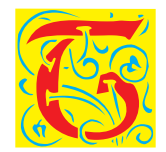

he Philosophy section comprises a wide variety of topics and issues, ranging from classical ontology and epistemology, to contemporary political philosophy. Respectively, the division into subsections corresponds to problematics discussed by the authors. The titles of the particular subsections cover the categories of philosophy or, due to the non-use of a dominant theme in the entire monograph, they are merely descriptions of the content.

The subsection entitled 'Eschatology' (papers by William Proios, Stella Marega, Shala Barczewska and Paulina Barańska) is to some extent an exception since the term is associated with theology, having little in common with philosophical enquiry per se. The reason for the inclusion is the broad scope of subjects discussed in the entire section, presented from multifarious angles and perspectives transcending the boundaries of philosophy as an academic discipline. This interdisciplinary and all-encompassing approach is undoubtedly connected with the turn of the centuries and the beginning of a new millennium, themes that feature in all papers in this section.

Friedrich Nietzsche is by far the most discussed philosopher (paper by Endre Kiss is exclusively devoted to Nietzsche), which is hardly surprising since his texts, in a natural way, recap paramount themes and leitmotifs discussed during the conference. Emphasis placed on the death and rebirth cycle, so prominent in Nietzsche's writings, is discernable here, regardless of the subject matter, approach and methods of enquiry.

Besides Nietzsche, it is Thomas Hobbes that stands out. This seems to be primarily connected to the recent political events and their reflection in specific problems and challenges faced by the contemporary Europe. Alternatives offered by Hobbes, most thoroughly exposed in the Leviathan, but also present in 
his other works, deserve a second look in what is generally perceived as the crisis of democracy as we know it.

Curiosity is the most widely discussed concept. Located on the boundary of the early modern and modernity, renaissance and enlightenment, curiosity is key to understanding the paradigm shift that occurred in that period. By extension, it could be perceived as fundamental for contemporary reasoning and Weltanschaaung. Curiosity comes to light in moments of transition that occur in different periods and philosophical/religious systems. Such liminal borderzones, understood literally and figuratively, are of interest to a number of authors, including Geoffrey Hinchliffe and Giorgos Kataliakos.

In general, the papers offer many new insights and enquiries into philosophical subjects, present in mainstream scholarship as well as research avenues located on the margins of current academic discourse. As a result, the authors discover or rediscover intriguing patterns and ideas even in the works of philosophers who are deemed as milestones in the development of Western thought: Spinoza, Hobbes, Descartes and Nietzsche. By so doing they show the ever-present actuality of philosophy that is, among others, concerned with questions of being and knowing in time; any moment and any time. 